\title{
Autism-Pathology and Psychoanalysis
}

\author{
Gabriel da Costa Duriguetto* and Ronaldo Chicre Araujo \\ Department of Psychology, Foundation President Antônio Carlos (FUPAC), Brazil
}

*Corresponding author: Gabriel da Costa Duriguetto, Department of Psychology, Foundation President Antônio Carlos (FUPAC), Rua Lincoln Rodrigues Costa, Brazil.

To Cite This Article: Gabriel da Costa Duriguetto, Ronaldo Chicre Araujo. Autism-Pathology and Psychoanalysis. Am J Biomed Sci \& Res. 2021 13(5). AJBSR.MS.ID.001907. DOI: 10.34297/AJBSR.2021.13.001907.

Received: 眥 July 22, 2021; Published: 眥 July 28, 2021

\section{Opinion}

Leo Kanner described the first cases of children with autism in 1943. He noted that they showed markedly reduced responses to the environment, degrees of lack of interest in human beings, avoidance of eye contact with other people and they preferred playing alone than playing accompanied. Over time, the difficulties of children with autism in social communication began to be perceived, manifested in deficits in emotional reciprocity and in non-verbal communication behaviors for social interaction [1].

In autism spectrum disorders, there may be negative changes in thinking, including impoverishment of ideas, positive changes in thinking, such as loosening of associations and inconsistency. Autism is a neurodevelopmental disorder that presents difficulties in social interaction and communication. Signs of Autism Spectrum Disorder can already be noticed before the age of three, although many children are diagnosed late. In this framework, there are restricted and repetitive behavior patterns, repetitive and/or stereotyped speech and object manipulation, hyper or hypoactivity to. These symptoms can cause significant damage to the social and professional functioning of the person's life [2]. It is often possible to observe the absence of initiating dialogue for interaction with another person and speech limitation, the language is sometimes stereotyped, repetitive or idiosyncratic. Many specialized psychological treatments have been developed, providing significant improvements in aspects of daily life and sociability of these children [1].

Even with the evolution of psychiatry to biologism, cognitivism and genetics, research studies have not been able to prove that true autism (considering the absence of any previous neurological damage) is of purely organic origin. Psychoanalysis was able, in this field, without excluding a priori the possibilities of multiple causes, to explain the psychic dimension of autism and to propose therapies enabling the care of autistic children in schools, clinics and specialized centers [3]. To differentiate autism from psychosis, alienation and separation can be considered as constituents of the subject's two operations of causation. The psychotic is not outside language but outside speech. The inscription in a discourse when it is conditioned by the separation operation, it must be taken into account that the psychosis out-of-discourse is its installation in the field of alienation. Autism can be situated on the side of alienation, a refusal to enter into it [4].

There are babies who, although they do not have any organic disorder, do not look at their caregiver, they do not smile, nor call her in case of distress. There is a failure to install the body image in the autistic child. Therefore, when faced with a non-installation of the specular relationship, pathologies are often evidenced that certainly reflect a non-installation of the fundamental symbolic relationship. The consequence of this is the failure of the constitution of the body image and the constitution of the self, which would correspond to the failure of alienation time, in the constitution of the subject. The fact that the child despises the presence of the other is due to a failure to insert his/her image. She does not make noises to ask for help because she is completely focused on herself [5]. To approach a clinical entity such as autism, Psychoanalysis considers the subject, the unconscious and language. In this precise case, in which the subject proves to be unfindable, this ethical requirement is maintained. The psychoanalytic clinic could not take the place of mortified knowledge in a doctrine, since it aims to make a subject appear with his live manifestations that will help in the treatment rhythm. Psychoanalysis operates with a decentralization in which 
the emphasis shifts from the innate character, that is, from the factor linked to the biological, to language disorders, which are not seen as formalized by the descriptive objectivity of the observer but considered in the transferential relationship [6].

\section{References}

1. Dalgalarrondo P (2000) Psychopathology and semiology of mental disorders. Medical Arts, Porto Alegre.

2. (2013) Diagnostic and Statistical Manual of Mental Disorders, ( $5^{\text {th }}$ Edn) (DSM-5).
3. Roudinesco E, Plon M (1998) Dictionary of Psychoanalysis. Rio de Janeiro, Jorge Zaha.

4. SOLER C (1997) The subject and the Other. In: FELDSTEIN Richard, FINK Bruce, JAANUS, Maire (Orgs.) To read Lacan's Seminar 11: The Four Fundamental Concepts of Psychoanalysis. Rio de Janeiro, ZAHAR. 52-57.

5. CHEMAMA R (1995) Dictionary of psychoanalysis. Larousse. Porto Alegre, Medical Arts.

6. Kaufmann P (1996) Encyclopedic Dictionary of Psychoanalysis. Rio de Janeiro, Jorge Zahar. 